\title{
Implementing disability policy in teaching and learning contexts - shop floor constructivism or street level bureaucracy?
}

Mike Wray ${ }^{1}$ and Ann-Marie Houghton ${ }^{2}$

Since 1995 the UK higher education sector has been required to implement national disability related legislation. This paper reports on a study which explored the role that policies play in influencing how staff support disabled students. In particular the extent to which staff in HE behave in similar ways to those described as street level bureaucrats by Lipsky (1980). Semi-structured interviews undertaken with 34 staff in the case study university provided the substantive data. Although there was little evidence to show that policy had a direct influence on practice, it was clear that staff made considerable efforts to support disabled learners and these efforts were based on values associated with providing an equitable experience for all students.

Additionally, staff were able to exercise discretion in the way they responded to disabled students and constructed responses to policies without significant influence from institutional managers, national legislation or broader policy discourse.

\section{Introduction}

In the UK, as in many countries in the developed world, legislation which seeks to redress issues of discrimination against disabled people ${ }^{3}$ has been in existence for a considerable number of years. However, there is conflicting evidence regarding the impact of disability legislation on the higher education (HE) sector. For example, previous research suggests that there are considerable barriers to participation for disabled students in learning and

\footnotetext{
${ }^{1}$ School of Law and Social Sciences, Centre for Education and School Partnerships, London South Bank University, London, UK. Contact: wraym2@Isbu.ac.uk School of Law and Social Sciences, Centre for Education and School Partnerships, London South Bank University, 103 Borough Road, London, SE1 OAA, UK.

2 Department of Educational Research, Lancaster University, Lancaster, UK

${ }^{3}$ Please note that one of the underpinning notions within this article is the social model of disability. The model suggests that people with impairments are disabled by the social, attitudinal and environment barriers which they face. Therefore, the authors use the terms disabled people and disabled students to reflect this idea.
} 
teaching contexts (Baron, Phillips, and Stalker 1996; Borland and James 1999; Holloway 2001; Jacklin et al. 2007; Vickerman and Blundell, 2010).

Despite a growing body of research into the experiences of disabled students in HE most of the existing studies have paid scant attention to the approach of academic staff in supporting these students and the role that policy plays in shaping these responses. The aim of the study discussed in this paper was to fill this gap in understanding by examining how staff implement policy relating to disability and teaching and learning contexts in an English university.

\section{The policy landscape}

The current wave of anti-discrimination policy in the UK can be traced back to 1995, with the introduction of the Disability Discrimination Act (DDA): after various amendments, the DDA was eventually consolidated into the Equality Act 2010 alongside other related policy. This legislation requires higher education institutions (HEIs) to anticipate and develop ways of responding to the needs of disabled students at all points on the student journey. The legislative framework in the UK reflects similar policy developments in other parts of the world such as the Americans with Disabilities Act and the Australian Disability Act. Relatedly, other broader frameworks such as the Salamanca agreement and the United Nations Declaration of Human Rights (UN General Assembly,1948) provided the context for legislative change and are very similar in their policy intentions.

One of the most significant policy instruments in the HE sector which affects the implementation of disability elements of this equality legislation, are the grants known as the Disabled Students' Allowances (DSAs). DSAs are available to individual disabled students to help pay for a range of support mechanisms and there is evidence to suggest that they 
are effective in supporting the progression and success of students who claim them (HEFCE 2009; NAO 2007). However, recent proposals for changes to this funding system have thrown into doubt the sustainability of the current approach. A number of significant measures which are aimed at 'modernising' (Willetts 2014) the DSA system for students who are funded by Student Finance England (SFE) have been implemented including a 'rebalancing', from the state to HEls, of the financial responsibility to deliver support and for a move towards more inclusive teaching and learning practice. This modernisation has been criticised as an attempt to disassemble the basis on which support is provided for disabled students and to remove legal obligations on the Government towards these students (NUS 2015).

Relatedly, in the last 20 years there have been a number of policy initiatives, which were intended to improve the learning experiences of disabled students. For example, pump prime funding was allocated for projects which aimed to improve access to various aspects of provision (HEFCE 2009), and since 1999, central funding for widening participation as part of the higher education funding councils' block grants ${ }^{4}$ has been disbursed (Bowes et al. 2013). Within the block grant there is an element specifically intended to recognise the increased costs of supporting disabled students. Additionally, HEls have utilised other funding sources, such as hardship funds, to pay for the support of disabled students and in a similar vein, Aimhigher initiatives provided the sector with funding to widen participation rates amongst underrepresented groups including disabled learners (DfES 2006).

\footnotetext{
${ }^{4}$ In the past the block grant has been known as Disability Premium Funding, or the Mainstream Disability Allocation and more recently is referred to by the HEFCE as being part of Student Opportunity funding streams.

Page $\mid 3$
} 
Despite national policy and various related initiatives being in place for over 25 years questions remain about the effect that the legislation has had on outcomes related to the HE sector. For instance, although there has been a noticeable rise in the numbers of students disclosing a disability (ECU 2013), there are variations in participation rates between different disability categories ${ }^{5}$ and in the participation patterns found in different subject areas ${ }^{6}$. Additionally, there are still inequalities in levels of participation, with disabled people still less likely to enrol on degree courses than non-disabled people (Li, Devine, and Heath 2008), have less success whilst in HE (ECU 2013), and have poorer employment outcomes upon graduation (AGCAS 2012). Relatedly, HEls appear reticent to respond to the organisational implications of national legislation. For examples, reviews of the requirements on HEls to produce more comprehensive statements of organisational planning in later iterations of the DDA, revealed that many HEls did not comply fully with the legislation (HEFCW 2009; Skill/Impact Associates 2006).

Doubts also remain regarding the extent to which change is evident within teaching and learning contexts. In a HEFCE funded review of their own policies, Harrison et al. (2009) highlighted a number of ways in which national HE policy was flawed; in particular, in relation to promoting the embedding of support within academic departments. Whilst the review (Harrison et al. 2009) pointed out that there are examples of good practice, HEFCE's response suggested that this practice 'remains at the margins in a number of institutions'

\footnotetext{
${ }^{5}$ E.g. in $2015 / 16$, the number of students disclosing a specific learning difficulty had risen to $5.2 \%$ $(\mathrm{n}=39675)$ of the total student population, from $0.86 \%(\mathrm{n}=5381)$ in 1997/98. In comparison only 577 additional students disclosed a hearing impairment: in 2015/16, 0.28\% ( $\mathrm{n}=2095)$ disclosed, compared to $0.24 \%$ ( $\mathrm{n}=1518$ ) in 1997/98 (HESA, 2016).

${ }^{6}$ E.g. in 2013 the lowest disclosure rate was $4.9 \%$ on business administration courses and the highest was $12 \%$ on veterinary courses (ECU, 2013).

Page $\mid 4$
} 
(HEFCE 2009, 16). Similarly, more recently commissioned HEFCE research into students with specific learning difficulties and students with mental health or intensive support needs, suggested that whilst there was evidence of progress in the past five years, there remains considerable diversity in the way teaching and learning considerations are addressed by institutions (HEFCE 2015a, 2015b).

\section{Disability related policy research in higher education}

There has been limited research carried out specifically into issues related to how academic staff in HE settings go about implementing disability related policy. Although there are some discussions about how staff should support disabled students in teaching and learning contexts (Aspland, Wray, and Harrison 2006; Thomas and May 2010) there is sparse empirical evidence linked to these notions.

However, there is a growing body of research that has examined the experiences of disabled students studying in HE in the UK. Such research suggests that significant barriers to disabled students' inclusion exist (Baron, Phillips, and Stalker 1996; Borland and James 1999; Tinklin and Hall 1999; Madriaga 2007; Coare, Houghton, and McDonnell 2007; Vickerman and Blundell, 2010), and many of these barriers are within the areas that teaching staff have a direct influence upon (Ball 2003; Hall and Healey 2005).

Within these studies there are some indirect discussions of how policy influences the approach taken to disability issues. For example, Baron, Phillips, and Stalker (1996) noted that, in the delivery of a social work course, disability was treated as a peripheral issue in comparison to other equality areas and where there was policy, such as in admissions, it was not being followed consistently. Borland and James (1999) report similar inconsistencies between academic departments in considering disability in the area of Page $\mid 5$ 
admissions and insufficient support has also been reported on teaching courses (Riddick and English 2006). This lack of support might be related to responses based on individual requirements rather than an inclusive focus on permanently removing barriers from the teaching space (Tinklin and Hall 1999). Organisational issues such as pressure from other policy areas might also play a part in militating against an inclusive approach. Matthews (2009) notes that concerns about other policies relating to data management had led to difficulties sharing information about disabled students and concerns about fitness to practice standards have been reported as causing barriers to nursing, teaching and social work courses (DRC 2007).

\section{Policy implementation theory}

The research project described in this article sought to explore some of the key ideas within the bottom up theoretical framework proposed by Lipsky (1980), in which he describes public sector workers as street level bureaucrats (SLBs). That is, in situations in which public servants face unlimited demands on their time and resources, they actively construct responses to policy through their day-to-day activities whilst being afforded a considerable level of discretion in their implementation. Through necessity and because of their situation, staff also develop a range of bureaucratic strategies to deal with their clients.

The context is one of a 'policy epidemic' (Levin, 1998) within the sector, where policies are 'passed on' without learning from previous initiatives and there is a feeling that policy is done to teachers rather than something which teachers have a say in (Levin, 1998). In HE in England, policy initiatives such as tripling of fees, removal of caps on student numbers, additional choice for students with $A$-level grades at $A A B$, have all been implemented with very little lead in time or indeed efforts to consult with the sector. 
Therefore, alongside an investigation of Lipsky's notions, the research also focussed on proposals that policy discourse around performativity (Ball 2003), commodification (Parker 2003) and the marketisation (Demaine 2002) of education, have encroached into the classroom, to such an extent that there is little room for professional judgement to remain. Therefore, the proposals here start with the assumption that, due to the prevailing policy discourse, the policy context in HE is one which is more akin to the shop floor than the street level. Furthermore, construction of policy is the overriding feature of staff responses in loosely coupled organisations (Weick 1976) such as universities, rather than bureaucratic processes which they employ.

Therefore, the aims of the research were to explore the question of how staff in HEls employ their agency around disability related issues within policy contexts which appear to be increasingly highly governed. Additionally, the research investigated how these staff go about constructing responses to the Equality Act 2010 in teaching and learning contexts and the extent to which they are influenced by such national legislation. As a corollary of these questions it sought to examine what HE staff say about their practice in relation to supporting disabled students in the classroom.

\section{Methodology}

The study took place in a medium sized HEl in England which was founded in the $19^{\text {th }}$ century. The institution gained HE status after the Further and Higher Education Act 1992 and as such would be described as being in the post-92 group of universities in the UK. Courses delivered are mainly based in the arts, social sciences, health and life sciences and business. There is only one STEM related course. Regarding disabled students, the university 
could be deemed to be performing well in comparison to national statistics in the HE population: there had been a steady increase in the numbers of students declaring disability and in the academic year $2014 / 15$ the figure stood at approximately $13 \%$ of all students.

The study took an interpretivist approach on the assumption that the act of policy implementation can be understood through the meanings that people give to policy texts (Ball 1994; Yanow 1996). Yanow $(1996,9)$ summarises this approach as:

one that focuses on the meanings of policies, on the values, feelings, and/or beliefs which they express, and on the processes by which those meanings are communicated to and 'read' by various audiences.

It was necessary therefore, to collect rich data and it was recognised that interpretations of data are context specific. Therefore the study adopted an ethnographic approach to produce an in-depth case study of one HEl in order to investigate the ways in which policy relating to disabled learners was implemented. Fieldwork was carried out over two and a half academic years and fieldnotes were taken of interactions at the institution during the course of the researcher's day-to-day work. Other strategies were employed to form a full picture of the organisation in relation to policy implementation: meetings of a disciplinary committee were attended, policy documents collected, relevant emails collated, screenshots of webpages taken and critical events (Woods 1993) noted.

This ethnographic fieldwork informed the substantive aspect of the research which was a series of semi-structured interviews (between 45-90 minutes) with 34 key staff in the university. These were mostly academic staff, but three administrative staff (including one senior academic manager) were also interviewed to provide a broader range of perspectives. None of the staff had specific roles or training related to supporting disabled students. This research used purposive sampling as it allows for 'the full scope of issues to Page $\mid 8$ 
be explored' (Cohen, Manion, and Morrison 2007, 168). Although staff were identified randomly (through the online telephone directory), care was taken to ensure that interviewees were based across all academic faculties of the university and that there were employed in a range of roles - lecturer, senior lecturer, course leaders. Only one person contacted declined to take part in the interviews. The research was cleared by the ethics committee within the case study university and mirrored good practice suggested in ethical guidance within the sector (BSA 2002). Participants were given details of the aims of the research in advance of interviews and were given the option to withdraw at any stage.

\section{Data analysis}

Data was analysed on an ongoing basis to form part of the continuous process that is recommended as good practice (Coffey and Atkinson 1996; Silverman 2005). Initially, a small sample of interviews were analysed with reference to the research questions, then coded for relevant issues. Codes were generated within this exercise through open coding (Gibbs 2007) and the interviews were reviewed in light of the research questions as suggested by Silverman (2005). Propositional statements were made during the process of coding to ensure consistency in the analysis.

The first cycle of coding (Saldana 2013) of the sample of interviews, developed an initial index and was carried out by hand using transcripts of the interviews. Second cycle coding used a refined version of initial index after deletion for repetition and under-utilised codes. Sub-coding was employed and sequential and descriptive coding were also used, where appropriate. In total 75 codes were used in the second cycle. The complete data set of interviews, fieldnotes and emails were then coded using the index Finally, the data was re-examined to provide thematic analysis and three broad themes were identified. 
It was important to continue the process of ensuring validity of the methodology and of the method of data analysis. Therefore, each interview was read with the idea of comprehensive data treatment (Silverman 2005) in mind so that instances of the conversation which related to the research questions were searched for throughout the transcription. Also, it was important to provide examples of areas where there might be contradictions between respondents in order to report 'deviant' cases (Silverman 2005) or discrepant information (Creswell 2003). These two processes alongside the fact that this account forms part of an iterative process, one in which it was intended to use constant comparative method and refutability principles (Silverman 2005), forms the basis of the argument that the study has validity.

\section{Analysis and Discussion}

Three broad themes emerged from the analysis of the data: policy construction, policy influence and implementation through praxis. There was evidence that these themes interact with one another in many situations and through this interaction, policies were being implemented. It is suggested therefore, that the way in which policies were being enacted is a dynamic and iterative process.

\section{Policy constructions}

When questioned about their knowledge of the national disability policy framework staff were unable to articulate an in-depth understanding of any specific aspects of the legislation. This was despite many of them attending training which was related to the latest version of the policy (i.e. Equality Act 2010), during the time of the research. A similar picture emerged when staff were asked about local policy at the case study institution. Nevertheless, all interviewees were aware that disability related legislation existed and Page $\mid 10$ 
some had vague ideas about what the intentions of the legislation were. For example, some interpretations were offered by interviewees around the notion of reasonable adjustments. Most of the interviewees had heard of the phrase and had some recollection of what was intended within the legislation. Most staff also seemed aware that the legislation is underpinned by the idea of providing disabled students with an equal opportunity to study alongside non-disabled students and they generally agreed with this notion.

However, the concept of equality of opportunity was conflated with ideas around fairness for all students. Staff were influenced by the idea that no student should be treated in a way which meant that they were given an unfair advantage. Additionally, staff were keen to ensure that everyone was assessed to the best of their abilities but were nonetheless conscious of ensuring that the principle applied to everyone:

'there is always that tension, I wouldn't say about being utterly fair, but if we do that for her, what about those other students? How are we moderating that? How are we keeping that equal?' Karl, lecturer, Arts.

'maybe their disability doesn't impair their ability to do essays and then I'm prejudicing the other students who have to get their essays in by a certain deadline, so that's an area of considerable debate amongst colleagues'. Xavier, lecturer, Health and Life Sciences.

Ideas and values implied by disability related policy appeared to cause friction and on a number of occasions, disability policy was over ridden by other concerns. At the heart of these concerns lay some confusion around the notion of levelling the playing field with respect to the support of disabled student and about injustices which equality legislation is intended to rectify:

'They have already received support from the support team, so why should they get it again by giving them extra time?' Jessica, lecturer, Business.

Similarly, concerns were expressed about the impact on academic standards, which some felt were being worn away by some of the problems which the delivery of support for 
disabled students generated. There were suggestions that sometimes, disabled students were being given an unfair advantage and that this was going beyond the remit for which the legislation was intended:

'you can't just give out endless time because there's also the credibility of the university and the standards'. Jocelyn, lecturer, Education.

As demonstrated in other research (McKenzie and Scheurich 2008; Vulliamy et al. 1997), personal values, identities and experiences of previous policy initiatives (Webb and Vulliamy 1999) were key to the way in which academic staff implemented policies. For example, one senior academic disclosed that they had dyslexia during the interview when describing their experience of support mechanisms as a student and a member of staff. Similarly, an administrative manager interviewed, was heavily involved in the appeals and complaints process within the organisation and was also a serving member of a national organisation within the sector which had oversight of these types of processes.

It has been proposed that one reason why staff at the chalkface may not engage in the detail of policy is that many policies are mediated by managers and administrative staff (Proudford 1998; Wallace 1991). In the case study university the role of the academic managers and course administrators was, at times, ambiguous in this respect. They did not feel that their role was to implement or disseminate information about disabled students. However, at other times during the fieldwork it was clear academic managers were expected to engage more with policies:

'but then nothing's come from Faculty to say that we should do that [the policy] I think maybe there's an expectation that's been missed... the fact that they think we're doing it.' Fiona, lecturer, Design.

These ideas were therefore also embroiled with notions of compulsion and part of the mediation process involved policies being filtered through the committees and formal 
structures of the organisation. A consequence of these formal processes was that there was concern that policies had been watered down, or that because they had been discussed at committee level, little remained which academic staff needed to implement. Also, because academic staff expected other staff to mediate policies they may have been lacking in motivation to engage in policies such as disability, which might appear to be at the periphery of teaching and learning activities.

Participants in the research were significantly influenced by the context of the institution within which they worked although they were often able to act with agency (Giddens 1984) in order to circumvent any issues which these influences caused. Regardless of the systemic bureaucracy which staff themselves faced they were willing to refract policy in order to find ways of supporting their students. In these instances, staff were constructing responses to internal policy and by doing so, the policies became their actions:

'We have been told by the university that we have to follow the guidance and not give anyone more than a week's extension but we ignore that because it's just not realistic with our students.' Rebecca, course leader, Education.

Lipsky (1980) described a lack of management influence in policy contexts but in the case study university the picture was more complex. For example, there was an attempt to manage the process of mitigating circumstances centrally but these attempts were circumvented by academic managers who perhaps related more to the needs of academic colleagues than with administrative edicts. This identification between public sector managers and their staff has been reported in other public sector contexts (Taylor 2007). However, the process of ongoing construction led to a somewhat chaotic approach to mitigating circumstances across the institution. This policy was in a state of flux during the time of the research and illustrates the fluid nature with which policies were being implemented. There was a constant construction of what the regulations meant and it was 
being interpreted differently across different departments. This was not resulting in positive outcomes for students and there was a good deal of confusion regarding the support which should be provided in these circumstances. Relatedly, some staff were wary of granting such support arrangements and issues of fairness were once again aired. Occasionally, staff were reticent about allowing such requests because they felt that some students were testing the system. This led to attempts by staff to stop all students from having extra time. Responses to this particular policy were therefore messy and at times led to barriers to the implementation of other policies such as the equality policy framework. This is a possible downside to 'street level constructivist' approaches to implementation and one which is perhaps more likely to occur in loosely coupled organisations (Weick 1976) such as universities.

\section{Policy influence}

There was very little evidence to suggest that disability related policy had a significant influence on the work of the participants in this study. Many of the staff indicated that they were aware of the policies but there were very few instances discussed in which they were directly implementing them:

'I do think it's important that we have some kind of standpoint to fall back on but whether it's really... having a big impact on the ground, I have to say I'm not sure it is'. Andrew, lecturer, Business.

One of the reasons perhaps, for this apparent lack of influence, was that there were a considerable number of other policies which existed in the institution. Edward et al. (2007) argue that whilst staff in the education sector have previously been able to respond to multiple initiatives, there is a danger that too much change can occur too quickly. Whilst staff recognise that policies can facilitate opportunities and benefits for learners, multiple 
initiatives also present bureaucratic demands and heap additional burdens on already stretched resources (Edward et al. 2007).

Although the case study university appeared to be highly regulated in terms of the numbers of policies which had been published, there was actually very little done to ensure that these policies were implemented. Management staff within the organisation did not play a particularly dominant role in policing these processes and procedures. Staff were largely left to their own devices, performing a constant balancing act in deciding what was important and what was not. This is a similar situation to that which Lipsky (1980) suggested in his original discussions of street level bureaucracy and is a possible reason why disability related policies, which are not central to teaching and learning delivery, were often only consulted in particularly complicated situations. For more straightforward scenarios staff were happy to implement localised practices or follow guidance from colleagues which was generally an approximation of what was written in policy documentation.

Additionally, different policies seemed to have differing levels of influence on interviewees: there seemed to be a hierarchy of influence. For instance, Elizabeth (lecturer, Health and Life Sciences) said she was more influenced by policies related to subject specific requirements (i.e. NHS) whereas she was much vaguer in her discussion of disability policy and 'HE kind of policies'. Whilst, academic staff may have agreed with the notion of inclusive practice as a principle, there were many other things vying for their time. It is difficult therefore, to see how such an issue would be prioritised and how it could play a significant role as a underpinning philosophy when it was of peripheral concern.

On a broader level, there was some evidence of the influence of other policy discourse, such as employability, from within the sector. There were three programme areas 
within the university that delivered courses which were overseen by professional bodies and competence requirements of these organisations influenced the thoughts of the staff involved in these teaching and learning scenarios. Staff were concerned about disabled students' abilities to meet the competences and the extent to which support could be provided. This was further extrapolated into placement situations and ultimately a concern for the ability of students to be competent in the workplace. On courses where there was no professional element staff were concerned about academic standards in a similar way. However, notions of performativity (Ball 2003) and the commodification of HE (Hursch 2005; Collini 2012) were less in evidence. It is difficult to conjecture as to the reasons for the lack of influence of performativity as there was a lack of data related to this, but it may have been the case that during the time of the research there was no direct impact of these broader policy influences in the classroom. There was little talk of students acting as consumers for example although some responses hinted at the requirement to 'save face' of the institution, but it is difficult to posit that this was a recognition of the influence of marketisation of HE. Therefore, it is not possible to say that staff within the university were acting in ways which might suggest a 'shop floor' context. Rather, there was evidence to suggest that they were still able to display a good deal of professional judgement which has been seen to be eroded in other educational settings such as in the schools sector (Osborn, McNess, and Broadfoot 2000; Poole 2008).

Additionally, it is suggested that equality legislation had little influence because it is just one policy area amongst many. On a day-to-day basis interviewees, within the present study, were engaging with policy frameworks which were more directly related to teaching and learning situations. These policies included such things as the university assessment framework, an academic workload model and the QAA framework. In the case study Page $\mid 16$ 
university, whilst it appears there is a highly organised and governed environment, it is difficult to envisage how any individual member of staff would be able to understand the whole range of policies in any detail so as to be able to use them in meaningful ways, except those which directly impacted on immediate and daily work situations.

\section{Implementation through praxis}

Praxis is defined here as implementation of policy through the day-to-day practice which is driven by underlying values within teaching and learning settings. Since staff rarely considered the content of disability related policy texts in any great depth, interpretations of policy usually came about from reflection on everyday practice. Relatedly, there was an underlying ethos within the organisation around the notion of inclusion and this value seemed to be at the core of many responses. At the case study university, staff responses to policy implementation reflect notions of praxis which suggest that teaching practices often go beyond the 'political-legal coercion' that is evident in policy frameworks (Ponte and Smit 2013). Practice attributed to serving the greater good of students, is also a feature of praxis (Gade 2014). Nevertheless, despite interviewees declared commitment to inclusivity, there were a number of teaching and learning dilemmas or tensions which cast doubt over the inclusivity of approaches adopted within the case study institution.

\section{Individualised approaches to teaching and learning adaptations}

At one end of the spectrum of teaching and learning approaches to disabled students are those which might be described as individualised. For instance, respondents described adaptations to the teaching space, such as ensuring there was an appropriate desk available or making sure a deaf student could sit at the front in order to hear clearly. On the face of it, many of these adaptations appear to be basic in terms of what staff were required to do in 
the classroom. However, many of the adaptations described had unique features or required the member of staff to devise a solution to the issue which involved an additional level of negotiation or problem solving. Interviewees were learning about the best way forward as they encountered these situations and the approaches were implemented as the need arose. In her first encounter with a blind student, Tina described the extra work which was required:

'it was a big learning curve... and we had to 'do a lot of extra work and preparation than we've ever done before'.

This resulted in an overall approach to implementation which was constructed over time:

'you just deal with person to person, as you get to know the students as you deliver the modules... I suppose equality is dealt with not so much as in a regimented way but more as a kind of touchy feely kind of way as we go through the course.' Tina, lecturer, Health and Life Sciences.

Sometimes the individualised approach was not enough and staff found themselves in intractable positions. Whilst implementation through praxis was in evidence there were inevitable restrictions on the efficacy of such an approach:

'We've got one area of the Faculty that's still inaccessible but there's a teaching space that you cannot get a lift to and it comes up again and again and years I've worked here it always comes up.' Joanne, senior academic manager, Arts.

Without intervention from more senior managers in providing a major change to the estate of the university, the problem described here was unlikely to be solved. Staff would attempt to do what they saw was in the best interests of the students but since they are at the chalkface of these interactions this sometimes led to them being placed in invidious positions.

Centralised support mechanisms also created dilemmas for the approach adopted in supporting disabled students within the classroom. Perhaps due to the availability of support services, academic staff within the university may have become reliant on the 
additional support that was provided and this may have been an impediment to delivery of inclusive teaching and learning:

'I don't think I have altered my practice.... they'll say I've got a dictaphone and can I record the sessions so that I can then go back to things that you've said later on'. William, lecturer/course leader, Health and Life Sciences.

In these situations, academic staff did not need to consider inclusive teaching and learning practice since support arrangements present in the classroom were organised and provided by central services rather than the academic department.

Implementation which is indicative of individualised approaches might be viewed as not being responsive to some of the intentions of national policy with its focus on anticipatory duties (DRC 2007). Additionally, this type of response could lead to added pressures on workloads, which is often suggested as a reason why teaching staff do not implement policies (Proudford 1998; Avramidis, Bayliss, and Burden 2000; Clegg 2003; Crump 2005). Nonetheless, support of disabled students was underpinned by values that staff held and which generally aligned with the principles which are contained within the legislative framework.

\section{Inclusive approaches}

Some of the staff interviewed in the study mentioned approaches which could be described as being inclusive (Ainscow 1997; Wray 2013). This term is used here to refer to those activities which might be of benefit to all learners and which do not present barriers to access for any learner. For example, one course leader in the arts department recounted teaching a small group of students which included three disabled learners, one of whom presented particularly complex challenges. However, this experience was not just a case of ensuring there were enough chairs in the room or teaching the group as she would any other group. Rather, it required altering the activities for the whole group in order to better Page $\mid 19$ 
include one of the disabled students. This member of staff explained that implementing this new way of teaching into her groups meant that all students were included and that the process had made her think about her teaching more generally. This was a theme which she continued to mention when she talked about how she had been thinking about some training she had been on and how it had made her reflect on the 'essay-centric' nature of much of HE.

Whilst some respondents were describing an inclusive approach which encapsulated the very essence of the way they approached teaching and learning, other staff developed this approach through a more consciously reflective process. These staff were learning about this approach through their experiences in day-to-day interactions with disabled learners but these interactions led them to think and deliver in more inclusive ways.

Inclusive approaches focus on an understanding of the disabled student as being part of the whole student body and it is not relevant to articulate the 'otherness' of disabled learners. This idea was reflected through some of the interviewees' responses which were framed in terms of their general duties to ensure that all learners succeeded to the best of their abilities and some of the interviewees saw it as their role to ensure that they taught in ways which would facilitate this process:

'Good practice? Being a good teacher; you want to be able to access anyone in your classroom and you want them to be able to access your teaching. Well what's the point of being there otherwise?' Gina, lecturer/course leader, Business. I'm kind of philosophically committed to this way of teaching because not only have I got so entrenched in it but I actually believe it because I've seen it works out well'. Fred, lecturer, Arts.

This approach to teaching and learning is illustrative of praxis, through the implementation of the principles of inclusive practice, which it could be argued is a central tenet of disability related national policy. 


\section{Conclusion}

Overall, this research demonstrates that staff within the case study university made considerable efforts to provide support for disabled students in teaching and learning contexts. However, their responses were largely based on individualised approaches to issues which may be structural in origin. A way of solving these tensions, adopted by a few teachers, was to develop an inclusive solution suitable for all students. This is contrary to much of the previous research which has focussed on the views of disabled students and of disability practitioners (Baron, Phillips, and Stalker 1996; Borland and James 1999; Madriaga 2007; Elliott and Wilson 2008; MacLeod and Green 2009), in isolation from a consideration of the teacher's position.

Relatedly, despite the lack of in depth knowledge or direct engagement with specific equality related policies, staff within the university were actively constructing responses to the policy context. These responses were aimed at providing equitable provision for disabled students and were underpinned by values associated with creating a rewarding learning experience for all students. The evidence therefore supports suggestions within bottom up understandings of implementation around the ability of staff to apply discretion when implementing policy. Although the approach adopted was unlike the bureaucratic model suggested by Lipsky (1980), the agency displayed by staff in constructing policy responses was suggestive of the 'street level'.

The idea that broader discourse was influencing the work of these staff was not convincing. Notions of performativity and managerialism did not seem to have encroached into teaching and learning contexts for these staff, in a significant way. There was no sense in which the classroom had become akin to a 'shop floor'. Staff at the case study university 
were more engaged in localised issues such as fairness and mitigating circumstances. These concerns were often linked to notions of academic standards. At times, efforts to support disabled students created tensions for academic staff because of such issues.

The study is limited in that it was based within one site and therefore there are problems in suggesting that the findings are generalisable to the HE sector or to education more broadly. However, the study offers inferential generalisation (Ritchie and Lewis 2003) and readers can assess the extent to which this context is similar to their own. To counteract issues related to generalisability, the research adopted a thick description of events and multiple methods of data collection and it is hoped that the data is recognisable to others in similar teaching and learning contexts.

In the field of education there is a lack of research which has examined qualitatively, first hand experiences of teaching and learning staff implementing equality legislation. Whilst schools research has tended to focus on the attitudes of teachers to disabled learners, HE research tends to explore issues related to teaching and learning theory. Little research exists which examines the role of policy within HE settings. Therefore, further research should be directed towards accounts of the experiences of teaching and learning staff in other contexts, perhaps exploring subject specific issues and reflections on classroom practice to create solutions. If improvements are to be made in disability support within $\mathrm{HE}$, changes need to originate from the analysis of empirical data, rather than policy alone (Scott, 1999, Kogan, 2000).

It has been argued (Wilde and Avrimidis 2011) that the attitudes of teaching staff towards disabled learners is indicative of a deficit model. These views are reinforced because learners are referred to as 'special' and require 'special' resources and extra training or 'specialised' skills which the teachers do not usually have. To an extent this 
approach was prevalent in the case study university. Although, teaching staff were clearly making adjustments to some of their teaching practice, a good deal of the reasonable adjustments which were provided within the organisation were delivered by central support services. This model reinforces an approach which means that teaching and learning staff are not expected to take responsibility for these requirements. In many ways this approach absolves them of the need to adhere to policy as faculty staff know that they can rely on central services to deal with issues.

The approach is also encouraged by the current system in which most reasonable adjustments within HEls which are related to providing support in teaching and learning contexts are funded by the Disabled Students' Allowances mechanism and are therefore generally managed by administrative staff within disability services. This system may be acting as a barrier to more inclusive approaches. One solution already exists within the sector: some universities have named contacts who are academic staff and act as a point of contact for disabled students and for staff. Relatedly, recent government announcements (Clark 2014) and cuts made to the DSA system have shifted the emphasis towards HEls fulfilling their legal obligations to provide reasonable adjustments which are anticipatory in nature i.e. are less based on individualised approaches and are introduced systemically. Universities need to continue to develop such strategies in order to move the onus into faculties and away from centralised student services staff so that inclusive practice becomes part of the everyday work of teaching and learning staff. In order for this to happen the emphasis needs to move away from services and procedures which are seen as additional, so that this approach becomes less relevant (HEFCE 2009). 


\section{References}

AGCAS. 2012. What Happens Next? A Report on the First Destinations of 2009/2010 Disabled Graduates. Sheffield: Association of Graduate Careers Advisory Service.

Ainscow, M. 1997. "Towards Inclusive Schooling.” British Journal of Special Education 24 (1): $3-6$.

Aspland, J., J. Wray, and P. Harrison. 2006. Supporting Disabled Students in Off-campus Settings: A Good Practice Quide, Kingston-Upon-Hull: The University of Hull. Avramidis, E., P. Bayliss, and R. Burden. 2000. “A Survey into Mainstream Teachers' Attitudes Towards the Inclusion of Children with Special Educational Needs in the Ordinary School in One Local Education Authority.” Educational Psychologist 20 (2): $191-211$.

Ball, S. J. 1994. Education Reform: A Critical and Post-structural Approach. Buckingham: Open University Press.

Ball, S. J. 2003. "The Teacher's Soul and the Terrors of Performativity.” Journal of Education Policy 18 (2): 215 - 228.

Baron, S., R. Phillips, and K. Stalker. 1996. "Barriers to Training for Disabled Social Work Students.” Disability \& Society 11 (3): 361 - 377.

Borland, J., and S. James. 1999. "The Learning Experiences of Students with Disabilities in Higher Eduation. A Case Study of a UK University.” Disability \& Society 14 (1): 85 101.

Bowes, L., L. Thomas, L. Peck, R. Moreton, and G. Birkin. 2013. The Uses and Impact of Access Agreements and Associated Spend. Bristol: OFFA.

BSA, 2002. Statement of ethical practice for the British Sociological Association. Durham: British Sociological Assocation.

Clark, G. 2014. Higher education: student support - changes to Disabled Students' Allowances. Written Ministerial Statement by the Minister for Universities and Science: https://www.gov.uk/government/speeches/higher-education-student-supportchanges-to-disabled-students-allowances-dsa--2

Clegg, S. 2003. "Learning and Teaching Policies in Higher Education: Mediations and Contradictions of Practice.” British Educational Research Journal 29 (6): 803 - 819.

Coare, P., A. Houghton, and L. McDonnell. 2007. Changing the Shape of the Box: Disability and Effective Inclusion. Leicester: NIACE. 
Coffey, A. and Atkinson, P. 1996. Making sense of qualitative data analysis: complementary strategies. Thousand Oaks CA: Sage.

Cohen, L., Manion, L. \& Morrison, K. 2007. Research methods in education, $6^{\text {th }}$ edition. Abingdon: Routledge.

Collini, S. 2012. What are Universities for? London: Penguin.

Cresswell, J. W. 2003. Research design: qualitative, quantitative and mixed methods approaches. 2nd edition. London: Sage.

Crump, S. 2005. "Changing Times in the Classroom: Teaching as a "Crowded Profession"." International Studies in Sociology of Education 15 (1): 31 - 47.

Demaine, J. 2002. Education Policy and Contemporary Politics. Basingstoke: Palgrave.

DfES. 2006. Widening Participation in Higher Education. Nottingham: Department for Education and Skills Publications.

DRC. 2007. Code of Practice (Revised) for Post-16 Providers of Education. London:

Disability Rights Commission.

ECU. 2013. Equality in Higher Education : Statistical Report 2013. Part 2: Students London: Equality Challenge Unit.

Edward, S., F. Coffield, R. Steer, and M. Gregson. 2007. "Endless Change in the Learning and Skills Sector: The Impact on Teaching Staff.” Journal of Vocational Education \& Training 59 (2): 155 - 173.

Elliott, T., and C. Wilson. 2008. The Perceptions of Students with Hidden Disabilities of their Experiences During Transition to Higher Education. East of England: Aimhigher.

Equality Act 2010, c. 15. London: Stationery Office.

Gade, S. 2014. "Praxis and Phronesis as Units of Analysis: Realising a Social Science that Matters in Practitioner Inquiry.” Reflective Practice: International and Multidisciplinary Perspectives 15 (6): 718-728.

Gibbs, G. R. 2007. Analysing qualitative data. London: Sage.

Giddens, A. 1984. The Constitution of Society. Cambridge: Polity.

Hall, T., and M. Healey. 2005. "Disabled Students' Experiences of Fieldwork.” Area 37 (4): $446-449$.

Harrison, M., L. Hemingway, A. Sheldon, R. Pawson, and C. Barnes. 2009. Evaluation of Provision and Support for Disabled Students in Higher Education. Bristol: Higher Education Funding Council for England.

HEFCE. 2009. Outcomes of HEFCE Review of its Policy as it Relates to Disabled Students. Bristol: Higher Education Funding Council for England.

Page $\mid 25$ 
HEFCE. 2015a. Understanding Provision for Students with Mental Health Problems and Intensive Support Needs. Bristol: Higher Education Funding Council for England. HEFCE. 2015b. Support for Higher Education Students with Specific Learning Difficulties. Bristol: Higher Education Funding Council for England.

HEFCW. 2009. Evaluation of Welsh Higher Education Institutions' Disability Equality Scheme. Cardiff: Higher Education Funding Council for Wales.

HESA (2016) Higher education student data. Accessed May 5, 2016. https://www.hesa.ac.uk/data-andanalysis/students

Holloway, S. 2001. "The Experience of Higher Education From the Perspective of Disabled Students." Disability \& Society 16 (4): 597 - 615.

Hursch, D. 2005. "Neo-Liberalism, Markets and Accountability: Transforming Education and Undermining Democracy in uhe United States And England.” Policy Futures in Education 3 (1): 3 - 15.

Jacklin, A., Robinson, C., O'Meara, L. \& Harris, A. 2007. Improving the experiences of disabled students in higher education. York: The Higher Education Academy.

Kogan, M. (2000) Higher education communities and academic identity, Higher Education Quarterly 54 (3): 207-216.

Levin, B. 1998. "An epidemic of education policy: (what) can we learn from each other?" Comparative Education 34 (2): 131 - 141.

Li, Y., Devine, F., and A. Heath. 2008. Equality Group Inequities in Education, Employment and Earnings: A Research Review and Analysis of Trends Over Time. London: Equality and Human Rights Commission.

Lipsky, M. 1980. Street-Level Bureaucracy: Dilemmas of the Individual in Public Services. New York: Russell Sage Foundation.

Madriaga, M. 2007. "Enduring Disablism: Students with Dyslexia and Their Pathways into UK Higher Education and Beyond.” Disability \& Society 22 (4): 399 - 412.

Matthews, N. (2009) Teaching the 'invisible' disabled students in the classroom: disclosure, inclusion and the social model of disability, Teaching in Higher Education 14 (3): 229 $-239$.

MacLeod, A., and S. Green. 2009. "Beyond the Books: Case Study of a Collaborative and Holistic Support Model for University Students with Asperger Syndrome.” Studies in Higher Education 34 (6): 631 - 646. 
McKenzie, K. B., and J. J. Scheurich. 2008. "Teacher Resistance to Improvement of Schools with Diverse Students.” International Journal of Leadership in Education 11 (2): 117 $-133$.

NAO. 2007. Staying the Course: The Retention of Students in Higher Education. London: National Audit Office.

NUS. 2015. Targeting Funding for Disabled Students in Higher Education from 2016/17 Onwards. London: National Union of Students. Unpublished report.

Osborn, M., E. McNess, and P. Broadfoot. 2000. What Teachers Do: Changing Policy and Practice in Primary Education. London: Continuum.

Parker, J. 2003. "Reconceptualising the Curriculum: From Commodification to Transformation.” Teaching in Higher Education 8 (4): 529-543.

Ponte, P., and B. H. J. Smit. 2013. "Education for All as Praxis: Consequences for the Profession." Professional Development in Education 39 (4): 455-469.

Poole, W. L. 2007. "Intersections of Organisational Justice and Identity under the New Policy Direction: Important Understandings for Educational Leaders.” International Journal of Leadership in Education 11 (1): 23 - 42.

Proudford, C. 1998. "Implementing Educational Policy Change: Implications for Teacher Professionalism and Professiona Empowerment." Asia-Pacific Journal of Teacher Education 26 (2): 139 - 150.

Riddick, B. \& English, E. (2006) "Meeting the standards? Dyslexic students and the selection process for initial teacher training", European Journal of Teacher Education 29 (2): $203-222$.

Ritchie, J. \& Lewis, J. eds., 2003. Qualitative research practice: a guide for social science students and researchers. London: Sage.

Saldana, J. 2013. The coding manual for qualitative researchers. 2nd edition. London: Sage.

Scott, S. S. (1997) Accommodating college students with learning disabilities: how much is enough? Innovative Higher Education, 22 (2): 85 - 99.

Skill/Impact Associates, 2006. Feedback to the Higher Education Sector on Disability Equality Schemes. London: Equality Challenge Unit.

Silverman, D. 2005. Doing qualitative research. 2nd edition. London: Sage. 
Taylor, I. 2007. "Discretion and Control in Education : The Teacher as Street-level Bureaucrat.” Educational Management Administration \& Leadership, 35 (4): 555 572.

Thomas, L., and H. May. 2010. Inclusive Learning and Teaching in Higher Education. York: Higher Education Academy.

Tinklin, T., and J. Hall. 1999. "Getting Round Obstacles: Disabled Students' Experiences in Higher Education in Scotland." Studies in Higher Education 24 (2): 183 - 194.

UN General Assembly. 1948. Universal declaration of human rights (217 [III] A). Paris.

Vickerman, P., and M. Blundell. 2010. "Hearing the Voices of Disabled Students in Higher Education.” Disability and Society 25 (1): 21 - 32.

Vulliamy, G., K. Kimonen, R, Nevalainen, and R. Webb. 1997. “Teacher Identity and Curriculum Change: A Comparative Case-Study Analysis of Small Schools in England and Finland." Comparative Education 33 (1): 97 - 116.

Wallace, M. 1991. "Coping with Multiple Policy Innovations in Schools: An Exploratory Study." School Organisation 11 (2): 187 - 209.

Webb, R. and G. Vulliamy. 1999. "Managing Curriculum Policy Changes: A Comparative Analysis of Primary Schools in England and Finland.” Journal of Education Policy 14 (2): $117-137$.

Weick, K. E. 1976. "Educational Organizations as Loosely Coupled Systems.” Administrative Science Quarterly 21 (1): 1-19.

Wilde, A. \& Avramidis, E., 2011. "Mixed Feelings: Towards a Continuum of Incusive Pedagogies." Education 3 - 13, 39 (1): 83 - 101.

Willetts, D. 2014. Higher Education: Student Support: Changes to Disabled Students' Allowances (DSA). Written statement to parliament 7th April 2014. https://www.gov.uk/government/speeches/higher-education-student-support-changesto-disabled-students-allowances-dsa $\% 20$

Woods, P. (1993) Critical events in education, British Journal of Sociology of Education, 14(4), pp. 355 - 371.

Wray, M. 2013. Developing an Inclusive Culture in Higher Education: Final Report. York: Higher Education Academy. Accessed 12 May 2016: https://www.heacademy.ac.uk/sites/default/files/inclusive_culture_report_0.pdf Yanow, D. (1996) How does a policy mean? Interpreting policy and organizational actions. Washington D. C.: Georgetown University Press. 
Page $\mid 29$ 